Arq. Bras. Med. Vet. Zootec., v.65, n.4, p.1183-1191, 2013

\title{
Teores proteicos em dietas para vacas Holandesas leiteiras em confinamento
}

\author{
[Protein contents in the diet of holstein milking cows in a tie stall] \\ V.R. Paiva ${ }^{1}$, R.P. Lana $^{2}$, A.S. Oliveira ${ }^{3}$, M.I. Leão ${ }^{2}$, R.M.A. Teixeira ${ }^{1}$ \\ ${ }^{1}$ Aluno de pós-graduação - Universidade Federal de Viçosa - Viçosa, MG \\ ${ }^{2}$ Universidade Federal de Viçosa - Viçosa, MG \\ ${ }^{3}$ Universidade Federal do Mato Grosso - Cuiabá, MT
}

\section{RESUMO}

Avaliou-se o efeito de dietas com níveis de proteína bruta - PB (10, 12, 14 e 16\% na matéria seca - MS) em vacas Holandesas mestiças com produção de leite médio (PL) de $13 \mathrm{~kg} / \mathrm{dia}$. Utilizou-se silagem de milho como volumoso, e a relação volumoso:concentrado foi de 75:25. Houve aumento linear para o consumo de todos os componentes da dieta, exceto para o consumo de carboidratos totais e carboidratos não fibrosos (CNF), que reduziram linearmente. O consumo dos nutrientes digestíveis totais (NDT) apresentou comportamento quadrático, com valor máximo estimado de 10,13kg/dia, na dose de $15,62 \%$ de PB na dieta. As digestibilidades de PB, EE, FDN e FDNcp aumentaram linearmente. Já os valores de digestibilidade de MS, MO, CNF e NDT apresentaram efeito quadrático, estimando-se ponto de máximo de 65,$09 ; 67,23 ; 78,35$ e 67,92 nas doses de 15,$39 ; 15,22 ; 15,62$ e 15,68\% de PB, respectivamente. A PL, sem e com correção para $3,5 \%$ de gordura, a variação de peso corporal e a composição do leite aumentaram linearmente, exceto para lactose, que não apresentou efeito. O nível de $14 \%$ de PB na dieta é o mais indicado para alimentação de vacas com produção média de $13 \mathrm{~kg} /$ dia de leite.

Palavras-chave: bovinos, consumo, nutrição, digestibilidade, leite

\begin{abstract}
The effect of diets with crude protein - CP (10,12, 14 and 16\% in dry matter - DM) levels in crossbred Holstein cows with milk production (MP) of $13 \mathrm{~kg} /$ day were evaluated. The feed consisted of $75 \%$ corn silage and $25 \%$ concentrate. There was a linear increase in the intake of all components of the diet, except for total carbohydrates and non-fibrous carbohydrates (NFC), which decreased linearly. The intake of total digestible nutrients (TDN) presented a quadratic effect, with maximum estimated value of $10.13 \mathrm{~kg} /$ day at a level of $15.62 \%$ of CP in the diet. The digestibility of CP, EE, neutral detergent fiber and neutral detergent fiber corrected for ash and protein increased linearly. However, the digestibility values for DM, OM, NFC and TDN presented a quadratic effect, with maximum estimated values of $65.09,67.23,78.35$ and 67.92 at levels of 15.39, 15.22, 12.62 and 15.68\% CP, respectively. The MP, without and with a correction to $3.5 \%$ fat, body weight variation and composition of the milk increased linearly, except for lactose which had no effect. The level of $14 \%$ CP in the diet is more suitable for feeding cows with average milk production of $13 \mathrm{~kg} / \mathrm{day}$.
\end{abstract}

Keywords: bovines, intake, nutrition, digestibility, milk

Recebido em 2 de novembro de 2011

Aceito em 9 de janeiro de 2013

E-mail: vrpaiva@yahoo.com.br

Apoio financeiro: $\mathrm{CNPq}$ 


\section{INTRODUÇÃO}

$\mathrm{Na}$ alimentação de vacas leiteiras, o consumo de matéria seca e sua digestibilidade determinam a quantidade de nutrientes disponíveis para mantença e produção de leite (NRC, 2001). A otimização do consumo de matéria seca pelas vacas leiteiras tem sido um dos objetivos do pecuarista para aumentar a disponibilidade de nutrientes para o animal e, assim, possibilitar que esse expresse maior produção.

Entre os fatores que afetam o consumo de matéria seca pelos bovinos está a deficiência de nitrogênio ruminal, na forma de amônia, aminoácidos ou peptídeos, que resulta em menor crescimento da microbiota ruminal por não atender seus requerimentos nutricionais (Sniffen et al., 1993). Com o menor crescimento microbiano, ocorre diminuição na digestão da parede celular e no consumo (Wilson e Kennedy, 1996). Há uma correlação relativamente alta entre o teor de proteína na dieta e a concentração de amônia ruminal que deve ficar entre 2 e $5 \mathrm{mg} / \mathrm{dL}$, considerados como adequados para maximizar a síntese de proteína microbiana e a digestão da parede celular (Satter e Slyter, 1974; Berchielli et al., 2006).

A proteína é o ingrediente mais requerido, depois da energia, para o desenvolvimento das funções metabólicas dos ruminantes. $\mathrm{O}$ requerimento proteico de vacas lactantes ocorre mediante a absorção de aminoácidos pelo intestino delgado proveniente da proteína microbiana verdadeira, proteína não degradada no rúmen e proteína endógena, que contribuem para o suprimento de proteína metabolizável. Entretanto, a ingestão de proteína bruta abaixo de $7 \%$ da MS da dieta proporciona menor desempenho animal (Van Soest, 1994). Por outro lado, a ingestão em excesso de PB está relacionada ao maior custo da dieta e à maior excreção de ureia na urina com desperdício de proteína e energia.

Variações nos teores de proteína bruta na dieta de vacas em lactação, contudo, proporcionam mudanças nos custos com alimentação e na excreção de compostos nitrogenados. Com isso, as avaliações de parâmetros produtivos tornamse necessárias para maior eficiência de sistemas produtivos leiteiros.

Assim, objetivou-se avaliar os efeitos dos níveis de proteína bruta na dieta sobre o consumo e a digestibilidade aparente dos nutrientes, a variação de peso corporal, a produção e a composição do leite de vacas em lactação.

\section{MATERIAL E MÉTODOS}

O experimento foi conduzido na Unidade de Ensino, Pesquisa e Extensão em Gado de Leite (UEPE-GL) do Departamento de Zootecnia (DZO), na Universidade Federal de Viçosa (UFV), durante o período de setembro a novembro de 2007.

Foram utilizadas 12 vacas mestiças da raça Holandesa, com média de $170 \pm 121$ dias de lactação, produção média de $13 \mathrm{~kg} /$ dia de leite e $570 \mathrm{~kg}$ de peso corporal. Os animais foram distribuídos em três quadrados latinos $(4 \times 4)$, balanceados de acordo com o período de lactação.

O experimento foi constituído por quatro períodos, com duração de 14 dias cada um, sendo os nove primeiros dias de adaptação às dietas e os demais para avaliação do consumo, da digestibilidade dos componentes da dieta, da produção de leite e de sua composição e da variação de peso corporal.

Os animais foram alimentados com quatro dietas com níveis de proteína bruta $(10,12,14$ e $16 \%$ na base da matéria seca (MS) total da dieta), sendo utilizada a silagem de milho na proporção de $75 \%$ da MS total em todas as dietas. A composição dos ingredientes das dietas experimentais, a composição nutricional dos concentrados e da silagem de milho e a composição nutricional e de nutrientes digestíveis totais das dietas experimentais encontram-se nas Tab. 1, 2 e 3, respectivamente. 
Teores proteicos em dietas...

Tabela 1. Composição dos ingredientes das dietas experimentais (\%MS)

\begin{tabular}{|c|c|c|c|c|}
\hline \multirow{2}{*}{ Itens } & \multicolumn{4}{|c|}{ \% PB na dieta (base da MS) } \\
\hline & 10 & 12 & 14 & 16 \\
\hline Silagem de milho & 75 & 75 & 75 & 75 \\
\hline Milho & 22,8 & 18,0 & 13,4 & 8,9 \\
\hline Farelo de soja & 0,3 & 5,32 & 10,0 & 14,7 \\
\hline Ureia + SA $(9: 1)^{1}$ & 0,62 & 0,57 & 0,57 & 0,57 \\
\hline Mistura mineral $^{2}$ & 1,28 & 1,11 & 1,00 & 0,90 \\
\hline Total & 100 & 100 & 100 & 100 \\
\hline
\end{tabular}

${ }^{1}$ Ureia com sulfato de amônio na proporção de 9 para 1.

${ }^{2}$ Mistura mineral $=$ fosfato bicálcico $(20 \%)$, calcário $(40,84 \%)$, cloreto de sódio $(32,44 \%)$, flor de enxofre $(5,84 \%)$, sulfato de cobalto $(0,003 \%)$, sulfato de cobre $(0,083 \%)$, óxido de zinco $(0,775 \%)$, iodato de potássio $(0,006 \%)$ e selenito de sódio $(0,005 \%)$.

Tabela 2. Composição nutricional dos concentrados e da silagem de milho

\begin{tabular}{lccccc} 
& \multicolumn{3}{c}{ \% de PB no concentrado (base da MS) } & Silagem \\
Itens & 15 & 23 & 31 & 39 & de milho \\
\hline MS (\%) & 88,79 & 89,15 & 87,6 & 87,66 & 29,11 \\
MO $^{1}$ & 94,58 & 93,96 & 93,67 & 92,99 & 94,98 \\
PB $^{1}$ & 14,84 & 22,89 & 31 & 39,11 & 7,11 \\
$\mathrm{EE}^{1}$ & 1,5 & 1,65 & 1,68 & 2,53 & 3,16 \\
$\mathrm{CT}^{1}$ & 82,27 & 73,44 & 65,01 & 54,97 & 84,71 \\
$\mathrm{FDN}^{1}$ & 17,14 & 21,77 & 26,32 & 31,78 & 52,31 \\
$\mathrm{FDNcp}^{1}$ & 15,51 & 20,05 & 22,51 & 25,03 & 51,02 \\
$\mathrm{CNF}^{1}$ & 65,13 & 51,67 & 38,69 & 23,59 & 32,40 \\
$\mathrm{Ca}^{1}$ & 1,18 & 1,29 & 1,09 & 1,05 & 0,17 \\
$\mathrm{P}^{1}$ & 0,61 & 0,66 & 0,68 & 0,69 & 0,15 \\
\hline
\end{tabular}

${ }^{1}$ Valores em porcentagem da MS

Tabela 3. Composição nutricional e de nutrientes digestíveis totais das dietas experimentais

\begin{tabular}{lcccc}
\hline & \multicolumn{4}{c}{$\%$ PB na dieta (base da MS) } \\
\cline { 2 - 5 } Itens & 10 & 12 & 14 & 16 \\
\hline MS (\%) & 44,57 & 44,67 & 44,08 & 44,08 \\
$\mathrm{MO}^{1}$ & 94,84 & 94,68 & 94,59 & 94,42 \\
$\mathrm{~PB}^{1}$ & 9,33 & 11,56 & 13,71 & 15,90 \\
$\mathrm{EE}^{1}$ & 2,78 & 2,81 & 2,84 & 3,07 \\
$\mathrm{CT}^{1}$ & 82,78 & 80,36 & 78,10 & 75,50 \\
$\mathrm{FDN}^{1}$ & 42,54 & 43,74 & 44,96 & 46,44 \\
$\mathrm{FDNcp}^{1}$ & 41,14 & 42,34 & 42,97 & 43,63 \\
$\mathrm{FDNi}^{1}$ & 11,09 & 11,05 & 11,12 & 11,15 \\
$\mathrm{CNF}^{1}$ & 40,24 & 36,62 & 33,14 & 29,06 \\
$\mathrm{NDT}^{1}$ & 61,69 & 64,74 & 65,29 & 65,17 \\
$\mathrm{Ca}^{1}$ & 0,42 & 0,45 & 0,40 & 0,39 \\
$\mathrm{P}^{1}$ & 0,26 & 0,28 & 0,28 & 0,28 \\
\hline
\end{tabular}

${ }^{\mathrm{T}}$ Valores em porcentagem da MS.

Os animais foram manejados em baias individuais, tipo tie stall, providas de cocho e bebedouro automático, onde receberam alimentação fornecida ad libitum duas vezes ao dia, após as ordenhas, na forma de mistura completa. As pesagens das dietas fornecidas e das sobras de cada tratamento aconteceram diariamente, para estimativa do consumo e também manutenção das sobras de alimento na ordem de 5 a $10 \%$, com base na matéria natural. No período de coleta, últimos cinco dias do período experimental, foram obtidas amostras dos alimentos fornecidos e das sobras e, no final, realizadas amostras compostas representativas por animal, as quais foram armazenadas em 
sacos plásticos a $-20^{\circ} \mathrm{C}$ para, posteriormente, serem analisadas.

Semanalmente, foi realizada coleta da silagem de milho e analisada a MS para ajuste da relação $\mathrm{V}: \mathrm{C}$ da dieta. As coletas de fezes foram realizadas diretamente na ampola retal, duas vezes ao dia, durante os três primeiros dias do período experimental (oito horas e 14h; 10h e $16 \mathrm{~h}$ e $12 \mathrm{~h}$ e $18 \mathrm{~h}$, respectivamente), sendo acondicionadas em sacos plásticos e armazenadas a $-20^{\circ} \mathrm{C}$.

O preparo das amostras compostas dos alimentos fornecidos, das sobras e das fezes foi realizado após serem descongeladas, pré-secas em estufa de ventilação forçada a $60 \pm 5^{\circ} \mathrm{C}$ durante 72 a 96 horas e, posteriormente, moídas em moinhos tipo Willey com peneira de $1 \mathrm{~mm}$. As amostras compostas foram acondicionadas em potes plásticos e as análises de matéria seca (MS), cinzas, extrato etéreo (EE) e proteína bruta (PB) dos alimentos, sobras e fezes seguiram as especificações descritas por Silva e Queiroz (2002). Os teores de fibra em detergente neutro (FDN) foram estimados segundo recomendações de Mertens (2002), assim como as correções para cinzas (Mertens, 2002) e para proteína (Licitra et al., 1996). A porcentagem de carboidratos totais (CT) foi obtida por: $100-(\% \mathrm{~PB}+\% \mathrm{EE}+$ \%Cinzas), os carboidratos não fibrosos (CNF) foram calculados como descrito por Hall (2000): $\mathrm{CNF}=100-[(\% \mathrm{~PB}-\% \mathrm{~PB}$ derivada da ureia + $\%$ ureia) $+\%$ FDN $+\%$ EE $+\%$ Cinzas $)]$. Para o cálculo de nutrientes digestíveis totais (NDT), utilizou-se a equação descrita no NRC (2001): $\mathrm{NDT}=\mathrm{PBD}+\mathrm{EED} \times 2,25+\mathrm{FDND}+\mathrm{CNFD}$, em que PBD, EED, FDND e CNFD representam os nutrientes digestíveis.

Para estimativa da excreção de MS fecal, utilizou-se fibra em detergente neutro indigestível (FDNi) como indicador interno, obtida após 240 horas de incubação ruminal dos alimentos, das sobras e das fezes, utilizando-se sacos de tecido não tecido (TNT) $\left(100 \mathrm{~g} / \mathrm{m}^{2}\right)$, como descrito por Casali et al. (2008). Após o período de incubação, os saquinhos foram lavados em água corrente até esta apresentar-se totalmente límpida. Logo após, os saquinhos foram submetidos à fervura em detergente neutro durante uma hora.
O peso dos animais foi obtido pela média das pesagens após as ordenhas, manhã e tarde, no início e no final de cada um dos períodos experimentais, e foi utilizado para calcular a variação de peso corporal.

As vacas foram ordenhadas, mecanicamente, duas vezes ao dia, às seis e às 16 horas, e nos últimos cinco dias foram coletadas as produções de cada animal para acompanhamento de seu desempenho. No $14^{\circ}$ dia, foram retiradas amostras, manhã e tarde, das produções de leite de cada vaca e, ao final, foi realizada amostra composta, proporcional à produção de leite. Parte desta amostra foi colocada em frascos plásticos com conservante (Bronopol $\left.{ }^{\circledR}\right)$, mantida entre $2 \mathrm{e}$ $6^{\circ} \mathrm{C}$, e encaminhada para o Laboratório de Análises de Qualidade de Leite da Embrapa Gado de Leite, no município de Juiz de Fora, MG, para análise dos teores de proteína bruta, gordura, lactose e extrato seco total, segundo a metodologia descrita pelo IDF (International..., 1996). A produção de leite foi corrigida para $3,5 \%$ de gordura (PLG) pela equação citada por Sklan et al. (1992); em que PLG $=(0,432+$ $0,1625 \times \mathrm{G}) \times \mathrm{kg}$ de leite e $\mathrm{G}=\%$ de gordura no leite.

A eficiência alimentar foi calculada para cada vaca, dividindo-se a produção média de leite pela ingestão média de MS de cada período experimental (Valadares Filho et al., 2000).

As variáveis obtidas foram submetidas à análise de variância e regressão, utilizando-se contraste ortogonal polinomial (efeito linear ou quadrático), conforme Lamberson e Kaps (2004). As análises estatísticas foram realizadas pelo programa SAS (Statistical..., 1989). Os três quadrados latinos foram analisados em conjunto e utilizou-se nível de $5 \%$ de probabilidade para o erro tipo I.

\section{RESULTADOS E DISCUSSÃO}

Houve aumento linear $(\mathrm{P}<0,05)$ nos consumos de matéria seca (MS) (kg/dia, \%PC e g/ $\left.\mathrm{kg}^{0,75}\right)$, matéria orgânica (MO), proteína bruta (PB), extrato etéreo (EE), fibra em detergente neutro sem correção (FDN) (kg/dia e \%PV) e corrigida para cinzas e proteína (FDNcp) com os aumentos de PB na dieta (Tab. 4). 
Teores proteicos em dietas...

Tabela 4. Consumo de nutrientes $\left(\mathrm{kg} / \mathrm{dia}, \% \mathrm{PC}\right.$ e $\left.\mathrm{g} / \mathrm{kg}^{0,75}\right)$ e de nutrientes digestíveis totais para as dietas experimentais

\begin{tabular}{|c|c|c|c|c|c|c|c|}
\hline \multirow[b]{2}{*}{ Itens } & \multicolumn{4}{|c|}{$\%$ PB na dieta (base da MS) } & \multirow[b]{2}{*}{ CV $(\%)$} & \multicolumn{2}{|c|}{ Efeito } \\
\hline & 10 & 12 & 14 & 16 & & $\mathrm{~L}$ & $\mathrm{Q}$ \\
\hline \multicolumn{8}{|c|}{$\mathrm{kg} / \mathrm{dia}$} \\
\hline MS & 12,85 & 13,91 & 14,91 & 14,90 & 7,43 & $0,0001^{1}$ & 0,0957 \\
\hline MO & 12,19 & 13,17 & 14,10 & 14,07 & 7,41 & $0,0001^{2}$ & 0,0941 \\
\hline PB & 1,20 & 1,60 & 2,0 & 2,36 & 9,32 & $0,0001^{3}$ & 0,3884 \\
\hline $\mathrm{EE}$ & 0,36 & 0,39 & 0,42 & 0,46 & 6,75 & $0,0001^{4}$ & 1,0000 \\
\hline $\mathrm{CT}$ & 10,64 & 11,17 & 11,64 & 11,26 & 0,26 & $0,0001^{5}$ & 0,1579 \\
\hline FDN & 5,47 & 6,08 & 6,70 & 6,93 & 7,71 & $0,0001^{6}$ & 0,1733 \\
\hline FDNcp & 5,29 & 5,89 & 6,41 & 6,51 & 7,59 & $0,0001^{7}$ & 0,0737 \\
\hline $\mathrm{CNF}$ & 5,17 & 5,09 & 4,94 & 4,33 & 6,97 & $0,0010^{8}$ & 0,0549 \\
\hline NDT & 7,91 & 9,00 & 9,73 & 9,68 & 8,10 & 0,0001 & $0,0281^{9}$ \\
\hline \multicolumn{8}{|c|}{$\% \mathrm{PC}$} \\
\hline MS & 2,36 & 2,51 & 2,68 & 2,67 & 6,83 & $0,0002^{10}$ & 0,1230 \\
\hline FDN & 1,00 & 1,10 & 1,20 & 1,24 & 6,70 & $0,0001^{11}$ & 0,1924 \\
\hline \multicolumn{8}{|c|}{$\mathrm{g} / \mathrm{kg}^{0,75}$} \\
\hline MS & 113,7 & 121,6 & 129,7 & 129,3 & 6,94 & $0,0001^{12}$ & 0,1100 \\
\hline
\end{tabular}

MS = matéria seca, $\mathrm{MO}=$ matéria orgânica, $\mathrm{PB}=$ proteína bruta, $\mathrm{EE}=$ extrato etéreo, $\mathrm{CT}=$ carboidratos totais, FDN $=$ fibra em detergente neutro, $\mathrm{FDNcp}=$ fibra em detergente neutro corrigida para cinzas e proteína, $\mathrm{CNF}=$ carboidratos não fibrosos. $\mathrm{L}=$ efeito linear; $\mathrm{Q}=$ efeito quadrático; $\mathrm{CV}=$ coeficiente de variação. ${ }^{1} \hat{\mathrm{Y}}=9,4976+$ $0,3573 \mathrm{~PB}\left(\mathrm{r}^{2}=0,88\right) ;{ }^{2} \hat{\mathrm{Y}}=9,1034+0,3292 \mathrm{~PB}\left(\mathrm{r}^{2}=0,88\right) ;{ }^{3} \hat{\mathrm{Y}}=-0,7557+0,1967 \mathrm{~PB}\left(\mathrm{r}^{2}=0,99\right) ;{ }^{4} \hat{\mathrm{Y}}=0,190+$ $0,1667 \mathrm{~PB}\left(\mathrm{r}^{2}=0,99\right) ;{ }^{5} \hat{\mathrm{Y}}=9,6592+0,1166 \mathrm{~PB}\left(\mathrm{r}^{2}=0,53\right) ;{ }^{6} \hat{\mathrm{Y}}=3,0569+0,2493 \mathrm{~PB}\left(\mathrm{r}^{2}=0,96\right) ;{ }^{7} \hat{\mathrm{Y}}=3,3132+$ $0,2087 \mathrm{~PB}\left(\mathrm{r}^{2}=0,93\right) ;{ }^{8} \hat{\mathrm{Y}}=6,3475-0,0916 \mathrm{~PB}\left(\mathrm{r}^{2}=0,75\right) ;{ }^{9} \hat{\mathrm{Y}}=-5,8002+2,0391 \mathrm{~PB}-0,06526 \mathrm{~PB}^{2}\left(\mathrm{R}^{2}=0,99\right) ;{ }^{10} \hat{\mathrm{Y}}=$ $1,8507+0,0541 \mathrm{~PB}\left(\mathrm{r}^{2}=0,87\right) ;{ }^{11} \hat{\mathrm{Y}}=0,6052+0,0409 \mathrm{~PB}\left(\mathrm{r}^{2}=0,96\right) ;{ }^{12} \hat{\mathrm{Y}}=87,809+2,751 \mathrm{~PB}\left(\mathrm{r}^{2}=0,88\right)$.

O aumento no consumo de MS, MO, FDN e FDNcp pode ser devido a um melhor aporte de compostos nitrogenados no rúmen, o qual proporcionou maior crescimento dos microrganismos fibrolíticos, resultando no aumento na degradação da fibra, na taxa de passagem e na utilização dos nutrientes. Colmenero e Broderick (2006b) observaram aumentos da atividade celulolítica no rúmen, indicada por aumento na concentração de acetato, quando forneceram dietas com níveis crescentes de PB para vacas leiteiras.

O consumo de extrato etéreo aumentou $(\mathrm{P}<0,05)$ devido às diferenças nos teores desse nutriente entre as dietas (Tab. 3) e também ao aumento do consumo de MS.

Os resultados foram semelhantes aos observados por Broderick (2003), que, ao utilizar vacas com 130 dias de lactação, com produção de leite de $34 \mathrm{~kg} / \mathrm{dia}$, observou aumento linear no consumo de MS (21,2; 22,1 e 22,6kg/dia) com aumento de PB dietética $(15,1,16,7$ e 18,4\% PB na base da MS, respectivamente).
Pereira et al. (2005b), entretanto, não observaram efeito no consumo de MS (média de $16,54 \mathrm{~kg} / \mathrm{dia})$ em vacas de produção de leite de $20 \mathrm{~kg} / \mathrm{dia}$ e 110 dias de lactação quando o nível de PB foi elevado de 11,3 para $14,4 \%$ na base da MS da dieta.

$\mathrm{O}$ aumento linear $(\mathrm{P}<0,05)$ no consumo de $\mathrm{PB}$ foi devido ao incremento no teor de PB da dieta, além do aumento no consumo de MS. Em contrapartida, a ingestão de carboidratos totais (CT) e de carboidratos não fibrosos (CNF) apresentou reduções lineares $(\mathrm{P}<0,05)$ devido à diminuição dos níveis de CNF e CT na dieta (Tab. 3). O consumo de nutrientes digestíveis totais (NDT) apresentou comportamento quadrático $(\mathrm{P}<0,05)$, sendo estimado valor máximo de $10,13 \mathrm{~kg} / \mathrm{dia}$, no nível de $15,62 \%$ de PB na dieta, base da MS.

Os valores observados e os estimados de consumo de MS, NDT e PB, em kg/dia, para vacas lactantes com $570 \mathrm{~kg}$ de peso corporal, produção de leite de $13 \mathrm{~kg} / \mathrm{dia}$ com $3,5 \%$ de gordura, segundo o Sistema Viçosa de Formulação de Rações (Lana, 2007), baseado no NRC (2001), apresentaram diferenças (Tab. 5). 
Paiva et al.

Tabela 5. Valores observados e os estimados de consumo (kg/dia) de matéria seca (MS), nutrientes digestíveis totais (NDT) e proteína bruta (PB) para as dietas experimentais

\begin{tabular}{lccccc} 
Itens & Exigência $^{1,2}$ & \multicolumn{4}{c}{ \% PB na dieta (base da MS) } \\
\cline { 3 - 5 } & & 10 & 12 & 14 & 16 \\
\hline MS & 14,1 & 12,85 & 13,9 & 14,91 & 14,9 \\
Diferença & & $-1,25$ & $-0,2$ & $+0,9$ & $+0,89$ \\
NDT & 8,47 & 7,91 & 9,00 & 9,73 & 9,68 \\
Diferença & & $-0,56$ & $+0,53$ & $+1,26$ & $+1,21$ \\
PB & 1,9 & 1,2 & 1,6 & 2,04 & 2,36 \\
Diferença & & $-0,7$ & $-0,3$ & $+0,14$ & $+0,46$ \\
\hline
\end{tabular}

${ }^{1}$ Sistema Viçosa de Formulação de Rações (Lana, 2007). ${ }^{2}$ NRC (2001).

As diferenças nos consumos de NDT e MS entre os valores observados e estimados ficaram próximos de zero no nível $12 \%$ de $\mathrm{PB}$. No entanto, o mesmo aconteceu para PB no nível $14 \%$ de PB na dieta. Esses dados mostram que, no nível de $12 \%$ de proteína, os animais tiveram suas exigências supridas de energia, correlacionando com a variação de peso corporal, que se aproximou de zero com esse nível de PB na dieta.

A variação de peso corporal apresentou aumentos $(\mathrm{P}<0,05)$ lineares, com valores observados de - 824,4; -74,4; 527,7 e 321,8g/dia para os níveis de $10 ; 12 ; 14$ e $16 \%$ de PB na dieta, respectivamente. Assim, nos níveis de 10 e $12 \%$ de PB, possivelmente ocorreu mobilização de reservas corporais para sustentar a mantença e a produção de leite dos animais. Esses resultados são parecidos com os encontrados por Pereira et al. (2005b), que trabalharam com vacas no terço médio da lactação e observaram variação de peso corporal próximo de zero no nível de $12,3 \%$ de $\mathrm{PB}$ na dieta. Kalscheur et al. (2006) não encontraram diferença no ganho de peso dos animais quando elevaram o nível proteico da dieta de 12,3 para $17,1 \%$ na base da MS.

Houve aumento linear $(\mathrm{P}<0,05)$ na digestibilidade da FDN e da FDNcp (Tab. 6). Esse efeito pode ser justificado pelos maiores consumos de PB, o que aumentou a disponibilidade de compostos nitrogenados no rúmen e resultou em estímulo à digestão da fibra. Segundo Broderick (2003), o maior aporte de compostos nitrogenados no rúmen pode estimular a digestão da fibra por resultar em maior crescimento de microrganismos fibrolíticos e aumento na concentração de ácidos graxos voláteis, como acetato, isobutirato e isovalerato (Colmenero e Broderick, 2006b).

Tabela 6. Digestibilidade aparente dos nutrientes e dos nutrientes digestíveis totais (NDT) para as dietas experimentais

\begin{tabular}{|c|c|c|c|c|c|c|c|}
\hline \multirow[b]{2}{*}{ Itens } & \multicolumn{4}{|c|}{$\%$ PB na dieta (base da MS) } & \multirow[b]{2}{*}{ CV (\%) } & \multicolumn{2}{|c|}{ Efeito } \\
\hline & 10 & 12 & 14 & 16 & & $\mathrm{~L}$ & Q \\
\hline MS & 60,68 & 63,57 & 64,57 & 65,09 & 2,63 & 0,0001 & $0,0242^{2}$ \\
\hline MO & 62,78 & 65,66 & 66,87 & 67,16 & 2,32 & 0,0001 & $0,0085^{3}$ \\
\hline PB & 54,91 & 61,94 & 68,14 & 72,60 & 3,70 & $0,0001^{4}$ & 0,0791 \\
\hline $\mathrm{EE}$ & 69,03 & 73,26 & 76,59 & 75,31 & 6,92 & $0,0035^{5}$ & 0,0781 \\
\hline FDN & 47,12 & 52,94 & 54,46 & 56,68 & 6,98 & $0,0001^{6}$ & 0,1078 \\
\hline FDNcp & 48,73 & 54,71 & 55,78 & 57,21 & 7,06 & $0,0001^{7}$ & 0,0539 \\
\hline $\mathrm{CNF}$ & 77,25 & 77,62 & 77,96 & 75,17 & 2,04 & 0,5706 & $0,0225^{8}$ \\
\hline $\mathrm{NDT}^{1}$ & 61,69 & 64,74 & 65,29 & 65,17 & 2,60 & 0,0001 & $0,0289^{9}$ \\
\hline
\end{tabular}

MS = matéria seca, $\mathrm{MO}$ = matéria orgânica, $\mathrm{PB}=$ proteína bruta, $\mathrm{EE}=$ extrato etéreo, $\mathrm{FDN}$ = fibra em detergente neutro, $\mathrm{FDNcp}=$ fibra em detergente neutro corrigida para cinzas e proteína, $\mathrm{CNF}=$ carboidratos não fibrosos. ${ }^{1}$ Valores em porcentagem da matéria seca. $\mathrm{L}=$ efeito linear; $\mathrm{Q}=$ efeito quadrático; $\mathrm{CV}=$ coeficiente de variação. ${ }^{2} \hat{\mathrm{Y}}=29,9234+4,5659 \mathrm{~PB}-0,1483 \mathrm{~PB}^{2}\left(\mathrm{R}^{2}=0,99\right) ;{ }^{3} \hat{\mathrm{Y}}=29,7319+4,9278 \mathrm{~PB}-0,1619 \mathrm{~PB}^{2}\left(\mathrm{R}^{2}=0,99\right) ;{ }^{4} \hat{\mathrm{Y}}=25,8656$ $+2,9242 \mathrm{~PB}\left(\mathrm{r}^{2}=0,99\right) ;{ }^{5} \hat{\mathrm{Y}}=59,2086+1,1037 \mathrm{~PB}\left(\mathrm{r}^{2}=0,75\right) ;{ }^{6} \hat{\mathrm{Y}}=33,1735+1,5097 \mathrm{~PB}\left(\mathrm{r}^{2} 0,91\right) ;{ }^{7} \hat{\mathrm{Y}}=36,8731+$ $1,3257 \mathrm{~PB}\left(\mathrm{r}^{2}=0,76\right) ;{ }^{8} \hat{\mathrm{Y}}=55,4899+3,6227 \mathrm{~PB}-0,1435 \mathrm{~PB}^{2}\left(\mathrm{R}^{2}=0,76\right) ;{ }^{9} \hat{\mathrm{Y}}=31,6679+4,6235 \mathrm{~PB}-0,1474 \mathrm{~PB}^{2}$ $\left(\mathrm{R}^{2}=0,99\right)$. 
Observou-se aumento $(\mathrm{P}<0,05)$ linear na digestibilidade aparente da $\mathrm{PB}$, o que pode estar relacionado com o efeito da diluição do nitrogênio metabólico fecal (Broderick, 2003; Pereira et al., 2005a; Colmenero e Broderick, 2006b).

As digestibilidades aparentes de MS, MO, CNF e NDT apresentaram respostas quadráticas, estimando valores máximos de 65,09, 67,23, 78,35 e $67,92 \%$, nos teores $15,39,15,22,15,62$, $15,68 \%$ de PB, base da MS.

Em vários trabalhos, foram demonstrados aumentos nas digestibilidades de MS, MO, PB e FDN com aumentos nos níveis de PB na dieta (Broderick, 2003; Pereira et al., 2005b; Colmenero e Broderick, 2006a), sendo relacionados ao maior suprimento de nitrogênio ruminal, o qual é essencial para o atendimento das exigências dos microrganismos que degradam a fibra do alimento, proporcionando aumento do consumo, da taxa de passagem e do aproveitamento dos nutrientes.

Observou-se efeito linear crescente $(\mathrm{P}<0,05)$ para produção de leite (PL), produção de leite corrigido (PLG), extrato seco total (EST) e extrato seco desengordurado (ESD) (Tab. 7). Estes resultados de PL, PLG, EST e ESD são consequências dos aumentos do consumo e da digestibilidade aparente dos nutrientes, o que possivelmente proporcionou um maior aporte de nutrientes na glândula mamária. São vários os nutrientes que dão suporte à glândula mamária para a síntese do leite, entre eles a glicose, os aminoácidos e os ácidos graxos. A produção de leite se correlaciona com a produção de lactose, que também apresentou efeito linear crescente $(\mathrm{P}<0,05)$, sendo esta responsável pelo estímulo de síntese do leite na glândula mamária.

Tabela 7. Produções de leite e de leite corrigido para 3,5\% de gordura, eficiência de utilização da matéria seca ingerida (kg de leite/kg matéria seca ingerida), porcentagem e produção diária dos constituintes do leite

\begin{tabular}{|c|c|c|c|c|c|c|c|}
\hline \multirow[b]{2}{*}{ Itens } & \multicolumn{4}{|c|}{$\%$ PB na dieta (base da MS) } & \multirow[b]{2}{*}{$\mathrm{CV}(\%)$} & \multicolumn{2}{|c|}{ Efeito } \\
\hline & 10 & 12 & 14 & 16 & & $\mathrm{~L}$ & Q \\
\hline \multicolumn{8}{|c|}{ Produção e eficiência } \\
\hline PL (kg/dia) & 11,61 & 12,30 & 13,63 & 13,88 & 9,48 & $0,0001^{1}$ & 0,5351 \\
\hline PLG (kg/dia) & 11,66 & 12,39 & 13,53 & 15,02 & 10,91 & $0,0001^{2}$ & 0,3669 \\
\hline Efic. MS & 0,86 & 0,88 & 0,89 & 0,90 & 8,00 & 0,3877 & 0,5092 \\
\hline \multicolumn{8}{|c|}{ Constituintes do leite } \\
\hline $\mathrm{PB}(\%)$ & 3,17 & 3,17 & 3,25 & 3,48 & 7,90 & $0,0075^{3}$ & 0,1273 \\
\hline PB (g/dia) & 368,3 & 391,3 & 440,7 & 484,7 & 12,60 & $0,0001^{4}$ & 0,5012 \\
\hline $\operatorname{GOR}(\%)$ & 3,53 & 3,52 & 3,48 & 4,00 & 10,98 & 0,0154 & $0,0361^{5}$ \\
\hline GOR (g/dia) & 409,1 & 435,2 & 470,1 & 555,2 & 13,91 & $0,0001^{6}$ & 0,1332 \\
\hline $\operatorname{LAC}(\%)$ & 4,68 & 4,73 & 4,74 & 4,66 & 2,97 & 0,7462 & 0,1216 \\
\hline LAC (g/dia) & 543,1 & 582,0 & 644,5 & 647,5 & 10,39 & $0,0002^{7}$ & 0,3337 \\
\hline $\operatorname{EST}(\%)$ & 12,40 & 12,43 & 12,50 & 13,21 & 4,89 & $0,0053^{8}$ & 0,0739 \\
\hline EST (kg/dia) & 1,44 & 1,53 & 1,70 & 1,84 & 10,58 & $0,0001^{9}$ & 0,6435 \\
\hline $\operatorname{ESD}(\%)$ & 8,87 & 8,91 & 9,02 & 9,22 & 3,23 & $0,0068^{10}$ & 0,3689 \\
\hline ESD (kg/dia) & 1,03 & 1,10 & 1,23 & 1,28 & 10,24 & $0,0001^{11}$ & 0,8602 \\
\hline
\end{tabular}

$\mathrm{L}=$ efeito linear; $\mathrm{Q}=$ efeito quadrático; $\mathrm{CV}=$ coeficiente de variação. ${ }^{1} \hat{\mathrm{Y}}=7,5742+0,4062 \mathrm{~PB}\left(\mathrm{r}^{2}=0,94\right) ;{ }^{2} \hat{\mathrm{Y}}=$ $5,8655+0,5602 \mathrm{~PB}\left(\mathrm{r}^{2}=0,98\right) ;{ }^{3} \hat{\mathrm{Y}}=2,6145+0,0502 \mathrm{~PB}\left(\mathrm{r}^{2}=0,78\right) ;{ }^{4} \hat{\mathrm{Y}}=162,1266+19,9341 \mathrm{~PB}\left(\mathrm{r}^{2}=0,98\right) ;{ }^{5} \hat{\mathrm{Y}}=$ $8,0828-0,7787 \mathrm{~PB}+0,0326 \mathrm{~PB}^{2}\left(\mathrm{R}^{2}=0,91\right) ;{ }^{6} \hat{\mathrm{Y}}=159,8155+23,6596 \mathrm{~PB}\left(\mathrm{r}^{2}=0,92\right) ;{ }^{7} \hat{\mathrm{Y}}=360,0157+18,7897 \mathrm{~PB}$ $\left(\mathrm{r}^{2}=0,91\right) ;{ }^{8} \hat{\mathrm{Y}}=10,9939+0,1263 \mathrm{~PB}\left(\mathrm{r}^{2}=0,70\right) ;{ }^{9} \hat{\mathrm{Y}}=743,70+67,903 \mathrm{~PB}\left(\mathrm{r}^{2} 0,99\right) ;{ }^{10} \hat{\mathrm{Y}}=8,2581+0,0574 \mathrm{~PB}\left(\mathrm{r}^{2}=\right.$ $0,91) ;{ }^{11} \hat{\mathrm{Y}}=583,88+44,244 \mathrm{~PB}\left(\mathrm{r}^{2}=0,98\right)$.

As reduções nos consumos de $\mathrm{CT}$ e de $\mathrm{CNF}$ podem reduzir a produção de propionato no rúmen, bem como o fluxo de amido para o intestino delgado. O propionato é o principal precursor da glicose no fígado e tem associação com o fluxo de glicose para a glândula mamária.
A síntese de lactose depende do fluxo de entrada de glicose na glândula mamária, pois representa o principal substrato para a síntese de galactose (Fonseca, 1995). Assim, a diminuição do consumo de CT e de CNF pode ter afetado a resposta em produção de leite e de lactose. 
O teor de lactose não teve efeito significativo $(\mathrm{P}>0,05)$, mas o teor de gordura apresentou comportamento quadrático $(\mathrm{P}<0,05)$, sendo estimado valor mínimo de $3,43 \%$, no nível de $11,94 \%$ de PB na dieta.

A produção de gordura no leite, por sua vez, aumentou $(\mathrm{P}<0,05)$ linearmente. Esse efeito está relacionado com a maior produção de leite e também com a diminuição $(\mathrm{P}<0,05)$ no consumo de $\mathrm{CNF}$ e o aumento $(\mathrm{P}<0,05)$ no consumo de FDN, o que possivelmente promoveu mudanças na flora ruminal e, assim, favoreceu o crescimento de microrganismos que degradam a fibra e, juntamente ao maior aporte de nitrogênio, alteraram a proporção dos AGVs, elevando o nível de acetato e $\beta-\mathrm{OH}$ butirato em relação ao propionato. $\mathrm{O}$ acetato e o $\beta-\mathrm{OH}$ butirato são precursores da via de novo de síntese de ácidos graxos de cadeia curta e média na glândula mamária de animais ruminantes. Além disso, o maior fornecimento de lisina e metionina na dieta, com o aumento da $\mathrm{PB}$, pode estimular a via de novo de síntese de ácidos graxos ou aumentar a síntese de quilomícrons e lipoproteínas de baixa densidade (NRC, 2001).

Resultados de comportamento linear crescente para produção de leite não corrigido e corrigido para 3,5\% de gordura, para produção de gordura e proteína foram encontrados por Broderick (2003) quando foram testadas dietas crescentes de PB $(15,1 ; 16,7$ e 18,4\%). Pereira et al. (2005b), ao trabalharem com vacas no terço médio da lactação, observaram resultados crescentes na produção de leite corrigido para $3,5 \%$ de gordura, na produção de gordura e proteína, mas não encontraram efeito na produção de leite sem correção e nas porcentagens de proteína e gordura, quando utilizaram dietas com níveis crescentes de PB $(11,3 ; 12,3 ; 13,3$ e $14,4 \%)$.

Os aumentos $(\mathrm{P}<0,05)$ lineares nos teores e na produção de proteína no leite talvez sejam em razão do maior consumo de MS e PB, resultando em aumento na síntese de proteína microbiana e em maior fluxo de proteína para o intestino delgado. O NRC (2001) afirma que a proteína microbiana é $64 \%$ metabolizável e que a proteína metabolizável é usada para a lactação com eficiência de 67\%. Assim, esta proporcionou à glândula mamária maior disponibilidade de aminoácidos presentes na corrente sanguínea, principais precursores para a síntese de proteína do leite.

\section{CONCLUSÃO}

Para vacas leiteiras Holandesas mestiças com produção média de $13 \mathrm{~kg} / \mathrm{leite} / \mathrm{dia}$, recomenda-se oferecer uma dieta com o nível de $14 \%$ de proteína bruta na MS.

\section{AGRADECIMENTO}

Aos estagiários Douglas, Hugo, Paulo Vítor, Poliana, Expedito, Tiago e Henrique, pelo empenho e pela dedicação durante a execução deste trabalho.

\section{REFERÊNCIAS}

BERCHIELLI, T.T.; PIRES, A.V.; OLIVEIRA, S.G. Nutrição de Ruminantes. Jaboticabal:Funep, 2006. 583p.

BRODERICK, G.A. Effects of varying dietary protein and energy levels on the production of lactating dairy cows. J. Dairy Scie., v.86, p.13701381, 2003.

CASALI, A.O.; DETMANN, E.; VALADARES FILHO, S.C. et al. Influência do tempo de incubação e do tamanho de partículas sobre os teores de compostos indigestíveis em alimentos e fezes bovinas obtidos por procedimentos in situ. Rev. Bras. Zootec., v.37, p.335-342, 2008.

COLMENERO, J.J.O; BRODERICK, G.A. Effect of dietary crude protein concentration on ruminal nitrogen metabolism in lactating dairy cows. J. Dairy Scie., v.89, p.1694-1703, 2006 a.

COLMENERO, J.J.O; BRODERICK, G.A. Effect of dietary crude protein concentration on milk production and nitrogen utilization in lactating dairy cows. J. Dairy Sci., v.89, p.17041712, 2006b.

FONSECA, F.A. Fisiologia da Lactação. Centro de Ciências Agrárias. Departamento de Zootecnia. Viçosa-MG: UFV, 1995. 137p.

HALL, M.B. Calculation of non-structural carbohydrate content of feeds that contain nonprotein nitrogen. University of Florida, 2000. P.A-25 (Bulletin 339,April-2000). 
INTERNATIONAL dairy federation - IDF. Whole milk determination of milkfat, protein and lactose content. Guide fir the operation of midinfra-red instruments. Bruxelas: 1996. 12p. (IDF Standard 141 B).

KALSCHEUR, K.F.; BALDWIN VI, R.L.; GLENN, B.P. et al. Milk production of dairy cows fed differing concentrations of rumendegraded protein. J. Dairy Sci., v.89, p.249-259, 2006.

LAMBERSON, W.R.; KAPS, M. Biostatistics for Animal Science. Cambridge: CABI, 2004. $445 \mathrm{p}$.

LANA, R.P. Sistema Viçosa de formulação de rações. 4.ed. Viçosa: Editora UFV, 2007b. 91p.

LICITRA, G.; HERNANDEZ, T.M.; VAN SOEST, P.J. Standardization of procedures for nitrogen fractionation of ruminant feeds. Anim. Feed Sci. Technol., v.57, p.347-358, 1996.

MERTENS, D.R. Gravimetric determination of amylase-treated neutral detergent fiber in feeds with refluxing in beaker or crucibles: collaborative study. J. AOAC Internat., v.85, p.1217-1240, 2002.

NATIONAL research council - NRC. Nutrient requirements of dairy cattle. 7. ed. Washington DC: National Academic Press, 2001. 381p.

PEREIRA, M.L.A.; VALADARES FILHO, S.C.; VALADARES, R.F.D. et al. Consumo, digestibilidade aparente total, produção e composição do leite em vacas no terço inicial da lactação alimentadas com níveis crescentes de proteína bruta no concentrado. Rev. Bras. Zootec., v.34, p.1029-1039, 2005a.

PEREIRA, M.L.A.; VALADARES FILHO, S.C.; VALADARES, R.F.D. et al. Consumo, digestibilidade aparente total, produção e composição do leite em vacas no terço médio da lactação alimentadas com níveis crescentes de proteína bruta no concentrado. Rev. Bras. Zootec., v.34, p.1040-1050, 2005 b.

SATTER, L.D., SLYTER, L.L. Effect of ammonia concentration on rumen microbial protein production in vitro. Br. J. Nutrition, v.32, p.199-205, 1974.

SILVA, D.J.; QUEIROZ, A.C. Análise de alimentos: métodos químicos e biológicos. 3.ed. Viçosa: UFV, 2002. 235p.

SKLAN, D.; ASHKENNAZI, R.; BRAUN, A. et al. Fatty acids, calcium soaps of fatty acids, and cottonseeds fed to high yielding cows. J. Dairy Sci., v.75, p.2463-2472, 1992.

SNIFFEN, C.J.; BEVERLY, R.W.; MOONEY, C.S. Nutrient requirement versus supply in dairy cow: Strategies to account for variability. J. Dairy Sci., v.70, p.3660-3178, 1993.

STATISTICAL analisys system - SAS. SAS/STAT user's guide. v.2, 4.ed. Cary, 1989. $846 \mathrm{p}$.

VALADARES FILHO, S.C.; BRODERICK, G.A.; VALADARES, R.F.D. et al. Effect of replacing alfalfa silage with high moisture corn on nutrient utilization and milk production. $J$. Dairy Sci., v.83, p.106-114, 2000.

VAN SOEST, P.J. Nutritional ecology of the ruminant. 2.ed. Ithaca, New York: Cornell University, 1994. 476p.

WILSON, J.R.; KENNEDY, P.M. Plant and animal constraints to voluntary feed intake associated with fibre characteristics and particle breakdown and passage in ruminants. Austr. J. Agricult. Res., v.47, p.199-225, 1996. 